\title{
Evolution and Role of Intraoperative Neurophysiological Monitoring in Intramedullary Spinal Cord Surgery: A 2-Year Series from Saudi Arabia
}

\author{
Saleh Baeesa', Emmanuel Labram², Mohammed Bin Mahfoodh², Mohammed Khalid², \\ Youssef Al-Said ${ }^{2}$ \\ ${ }^{1}$ Division of Neurosurgery, Faculty of Medicine, King Abdulaziz University, Jeddah, KSA \\ ${ }^{2}$ Division of Neurosurgery, Department of Neurosciences, King Faisal Specialist Hospital and Research Center, \\ Jeddah, KSA \\ Email: sbaeesa@kau.edu.sa
}

Received 6 June 2014; revised 6 July 2014; accepted 17 July 2014

Copyright (C) 2014 by authors and Scientific Research Publishing Inc.

This work is licensed under the Creative Commons Attribution International License (CC BY). http://creativecommons.org/licenses/by/4.0/

\section{Open Access}

\section{Abstract}

Introduction: Despite recent advances in neuroimaging and microsurgical techniques, surgical resection of spinal cord tumours remains a challenge. However, the evolution with advances and refinement of neurophysiological equipment and methodologies, intra-operative neurophysiological monitoring (IONM) is now regarded as an essential adjunct to the surgical management of intramedullary spinal cord tumours. This study aims to report our preliminary experience with IONM and emphasise its effective role of achieving maximum tumour resection and minimising neurological injury. Methods: This is a retrospective study performed at our institution between July 2012 and August 2013. It included a cohort of 6 consecutive patients presented with intramedullary spinal cord tumours. Their mean age was 26 years (range, 4 months - 37 years), all were males, and the mean follow up was 11.6 months. Results: We combined the use of somatosensory evoked potentials (SSEPs) and motor evoked potentials (MEPs) in spinal cord surgery. SSEPs are monitored during the incision of the dorsal midline of the spinal cord and this was used in two of our patients and MEPs were used as an essential monitoring during the tumour resection. In addition, we used free-running electromyography (EMG) and muscle MEPs (mMEPs) during tumour resection. Four of our patients (two with ependymoma, one with ganglioglioma, and one with pilocytic astrocytoma) had complete tumour resection and two patients (pilocytic and diffuse astrocytoma) had IONM changes during surgery and had partial tumour resection. At 6-month follow up all our patients had made a good recovery with no new neurological sequelae. Conclusion: This small series and literature review is presented to add and improve the understanding of IONM in intramedullary spinal cord procedures and to reinforce the importance of IONM in optimising tu- 
mour resection and neurological outcome. Our series confirm that without D-wave monitoring, free-running EMG and MEP monitoring during tumour resection remain an important adjunct. We also draw attention to the fact that changes in the free-running EMG occur before any changes in the MEPs are noted.

\section{Keywords}

\section{Neurophysiological Monitoring, Intramedullary Spinal Cord Surgery}

\section{Introduction}

Intramedullary spinal cord tumours are rare, accounting for approximately $2 \%$ of adult and $10 \%$ of paediatric central nervous system neoplasms [1]. Surgical resection of intramedullary spinal cord tumours carries a significant risk of causing neurological dysfunction. IONM is now regarded as an essential adjunct to the surgical management of these tumours. Evoked responses are constantly monitored for changes that will alert the surgical team so that actions are altered or avoided to reduce the risk of post-operative neurological deficit.

Our study aims to report our preliminary two-year experience and review the history and evolution of IONM in the surgical management of intramedullary spinal cord tumours.

\section{Methods}

\subsection{Subjects}

The use of IONM for intramedullary spinal cord tumours was started in the King Faisal Specialist Hospital and research centre in Jeddah May 2012. We reviewed the records of six patients who presented with intramedullary spinal glioma from July 2012 to August 2013. They were all male adults with the exception of a 4-month-old baby. The mean age was 26 years (average, 4 months to 37 years). A summary of the cases is presented in Table 1 .

\subsection{Presentations}

All patients presented with mild to moderate sensory and/or motor symptoms. Pain was a prominent clinical feature in only one of the patients. The neurological evaluation was performed according to American Spinal Injury (ASIA) Impairment Score (AIS). Pre-operative clinical assessment to document sensory (tactile discrimination, vibration, joint/muscle sensation) and motor deficit is important to help compare and verify changes during the post-operative clinical evaluation.

\subsection{Preoperative Workups}

Whole spinal magnetic resonance imaging (MRI) scans were performed in all patients. The neurophysiology team who carry out baseline nerve conduction tests (SSEPs and EMG) where possible and appropriate also assesses the patients. All these preoperative examinations and assessments will document any deficits that may limit intraoperative monitoring.

\subsection{Intraoperative Monitoring Techniques}

All cases were performed under general anaesthesia, with 3-pins head fixation (except the 4-month-old baby) for cervical-thoracic lesions. We used Propofol and Fentanyl infusions [2] in the anaesthetic management of the patients to enable intraoperative neurophysiological monitoring particularly of MEPs to be carried out and is the standard for all our patients. Halogenated anaesthetic agents are not used. Short acting muscle relaxants were used for intubation only and discontinued during the operative procedure to allow continuous monitoring of MEPs. The median nerve at the wrist and the posterior tibial nerve behind the medial malleolus at the ankle were used for monitoring SSEPs. Subdermal needle electrodes were used. To elicit MEPs, transcranial electrical stimulation through scalp electrodes was used. mMEPs were recorded and monitored via electrodes inserted in 
the upper and lower limb muscles at about $3 \mathrm{~cm}$ apart. D-wave monitoring using epidural electrodes was not used in our patients. Baseline SSEPs and MEPs recordings were obtained before and after the patient is positioned on the operating table and also before the dura is opened.

After laminectomy and durotomy of the accurate level were performed, using intraoperative fluoroscopy, the identification of the midline of the spinal cord may be difficult because of the distorted anatomy as a result of cord rotation, oedema, and local scar formation and neovascularisation. This makes the use of standard anatomical landmarks difficult and misleading. In 2 of our patients, antidromically elicited SSEPs, as demonstrated by Quinones-Hinojosa et al. [3] were used to define the physiologic midline.

SSEPs were monitored continuously during the incision of the dorsal spinal cord midline and myelotomy. Irrigating bipolar cautery and a diamond blade were used and sometimes this could lead to a significant decrease in the amplitude or complete loss of the SSEPs as reported in the literature [1] [4]. The changes in the SSEPs tend to recover very quickly after a pause in the manipulation of the cord and irrigation of the field with warm normal saline. During dissection of the tumour, close and careful attention is paid to MEPs. After tumour resection, approximating the pial edges with $7 / 0$ absorbable sutures repaired the myelotomy site and the dura was closed in watertight fashion.

\section{Results}

All our patients had, SSEPs, free-running EMGs and mMEPs monitoring. Two patients ( 3 and 6) in Table 1 had altered intraoperative monitoring and had transient worsening of motor deficit after surgery, which improved to baseline before discharge home. These two patients had partial resection of their astrocytoma whilst the other 4 had complete resection of their tumours Figure 1 and Figure 2. None of the patients had worsening of their sensory deficit or other surgical complication.

Table 1. Clinical summary of the patients in our series.

\begin{tabular}{cccccc}
\hline Age/Sex & Presentation (AIS) & Spinal Level & Pathology & Resection & AIS Outcome (months) \\
\hline $31 \mathrm{yr} / \mathrm{M}$ & Quadriparesis (D) & C3-T3 & Ependymoma & Complete & E (16) \\
$4 \mathrm{mo} / \mathrm{M}$ & Quadriparesis (C) & C3-T5 & Ganglioglioma & Complete & E (15) \\
$37 \mathrm{yr} / \mathrm{M}$ & Quadriparesis (D) & C1-C3 & Pilocytic Astrocytoma & Partial & E (12) \\
$30 \mathrm{yr} / \mathrm{M}$ & Quadriparesis (D) & C1-C7 & Pilocytic Astrocytoma & Complete & D (11) \\
$27 \mathrm{yr} / \mathbf{M}$ & Quadriparesis (D) & C4-C6 & Ependymoma & Complete & E (10) \\
$30 \mathrm{yr} / \mathrm{M}$ & $\begin{array}{c}\text { Paraparesis (C) with impaired } \\
\text { sphincters control }\end{array}$ & T12-L1 & $\begin{array}{c}\text { Diffuse fibrillary } \\
\text { Astrocytoma }\end{array}$ & Partial & $\begin{array}{c}\text { E (6) with recovery of sphincter } \\
\text { functions }\end{array}$ \\
\hline
\end{tabular}

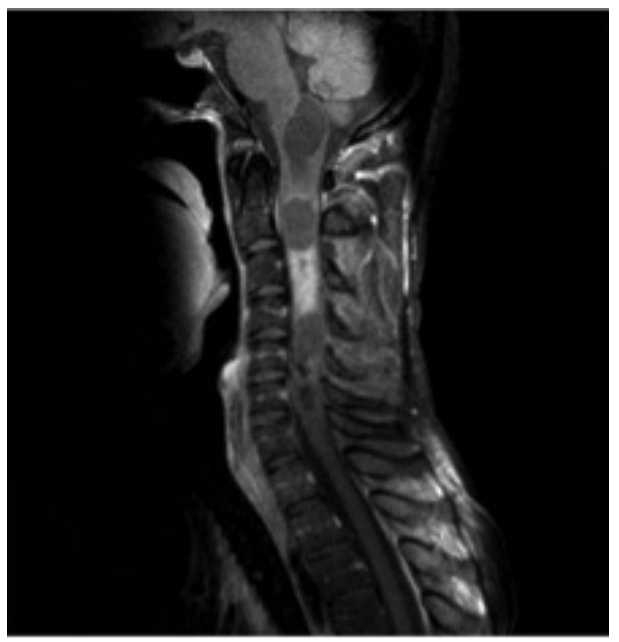

Figure 1. Preoperative contrast enhancing T1-WI MRI (patient no. 4) demonstrating large intramedullary glioma. 


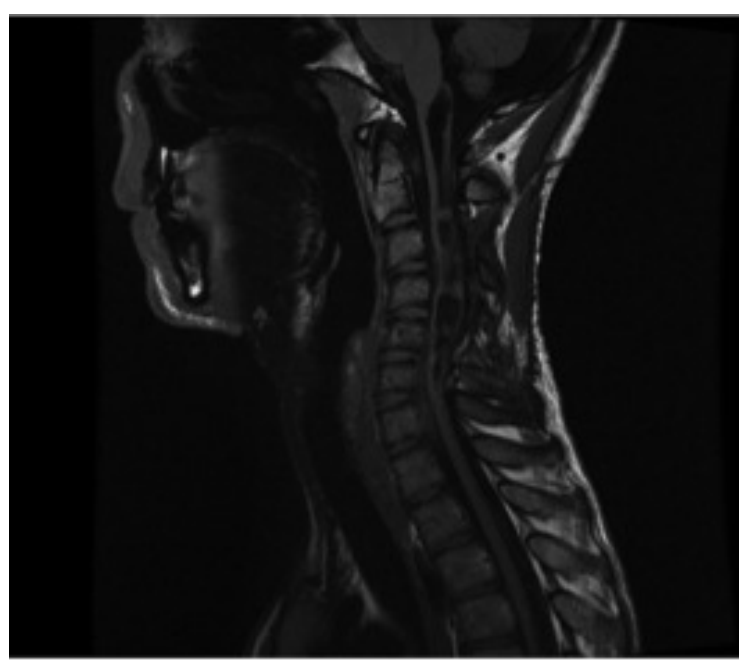

Figure 2. 12-month Postoperative follow up T1-WI MRI with contrast (patient no. 4) demonstrating no residual tumour.

At mean postoperative follow up of 11.6 months (range, 6 - 16 months), all the patients had improvement in their clinical neurological status and mobilising independently and all the adults were back to their preoperative employment status.

\section{Discussion}

In 1911, Elsberg and Beer as indicated already, in New York, first reported a successful two-stage resection of an intramedullary spinal cord tumour [5]. Following their report, many surgeons advocated a conservative approach to include a biopsy and radiotherapy regardless of the histopathology of the tumour due to the significant neurological deficits following surgical resection.

However, coupled with the introduction, development and refinement of microsurgical techniques using ultrasonic aspirator and laser technologies and better radiological imaging with MRI, resection of intramedullary tumours is now the primary treatment modality and radiotherapy is limited to recurrent or malignant neoplasms [6]. The majority of intramedullary spinal cord tumours are benign and therefore gross total resection if possible may result in long-term survival [7] [8]. IONM is an additional tool in helping achieve safe maximum tumour resection and to also minimise neurological injury [9].

IONM is continually evolving technology whose primary objective is to localise and monitor neuronal function to enable and help preserve neural integrity. Du Bois Reymond, in 1848, was the first to demonstrate the action potential of nerves and is also credited with the first EMG after he described muscle electrical activity [10], while SSEP was much later recorded in 1947 by Dawson [11]. Spinal cord neurophysiological monitoring techniques were developed in the 1970s and SSEPs were first used to monitor spinal cord function during surgical deformity correction procedures [12]. Since the mid-1980s, SSEPs monitoring has been refined and now become the mainstay of intra-operative spinal cord monitoring technique [13]-[16].

Intra-operative monitoring of the facial nerve was probably the first motor system to be monitored. In 1980, Merton and Morton [17] reported a technology to help stimulate the brain trans-cranially and opened the doors for motor tract monitoring. After overcoming some technical difficulties, IONM of the spinal cord motor pathway was developed and since the 1990s, has gained widespread use [18] [19].

Before the advent of MEPs in spinal cord tumour surgery, only SSEPs were used and records of postoperative neurological deficit were noted despite unchanged intra-operative SSEPs [20]. Kearse and his colleagues reported good sensitivity but poor specificity of SSEPs and this limited complete resection of tumours as a result of the high rate of false positive findings [21]. In 1997, Morota introduced the use of D-wave (epidural MEPs) monitoring and concluded that this appeared as a better predictor of functional outcome compared to the clinical motor status [14]. D-wave recordings when available are said to be important and robust in providing specific and quantitative information on the integrity of the spinal cord [4] [14] [22] [23]. However, it still does have 
some limitations because it does not distinguish between the lateral corticospinal tracts and therefore cannot differentiate between different muscle groups. D-wave cannot be recorded below T12 and scarring impairs electrode placement [22].

The introduction of the multi-pulse technique by Taniguchi and colleagues in the mid-1990s resolved the problem of anaesthesia-induced blocking of the $\alpha$-motor neurones, and since then MEPs have gained widespread and successful use in IONM of intramedullary spinal cord tumour procedures [23].

mMEPs recordings were used in all of our patients. One of the patients had unilateral decrease and another had unilateral loss of mMEPs during the operative procedure. Both of these patients (case 3 and 6) shown in Table 1 had transient postoperative worsening of motor function, which recovered over a period of days before discharge from hospital. Following significant decrease in the amplitude or loss of MEPs, as evident in the literature, one has to stop the resection and manipulation of the spinal cord [24]-[26]. Warm normal saline irrigation is used to help dilute out the potassium, which accumulates, and induce blockage of conduction and also clear out the blood and its breakdown products. Increase in the mean arterial blood pressure improves local perfusion and averts any incipient ischaemic damage.

It has been reported that using D-wave recordings, one can use 50\%decrease in the amplitude as a cut off criteria for determining potential irreversible injury to the cord [26]. However with mMEPs recordings, different authors including our series have used changes in the morphology, amplitude or latency as criteria for determining potential damage to the cord [4] [14] [27]-[29]. These parameters are however extremely variable even in the neurologically intact patient. Sala and his colleagues, [26] advised considering the use of presence/absence in mMEPs responses which they found had no false negative results and $<10 \%$ false positive results in their series and as reported by other groups [27] [30].

We used free running EMG as described by Skinner and his colleagues for all our patients [18] Changes from the baseline studies were detected in 2 patients (Figure 3 ).

Changes in the free-running EMG anticipated mMEPs changes (Figure 4).

But, after pausing and irrigating with warm saline, the changes returned to normal (Figure 5).

Both of these patients had transient motor deterioration, which recovered to baseline before discharge home.

Some of the risks relating to the use of trans-cranial multi-pulse stimulation are direct neural tissue damage and seizures but none of our patients experienced this. The seizure risk is extremely low in the reported data so far. Other reported risks include minor lacerations and haematoma of the tongue as a result of the strong contractions of the muscles of mastication. Protecting the tongue and using a padded airway protector usually avoids this complication [31].

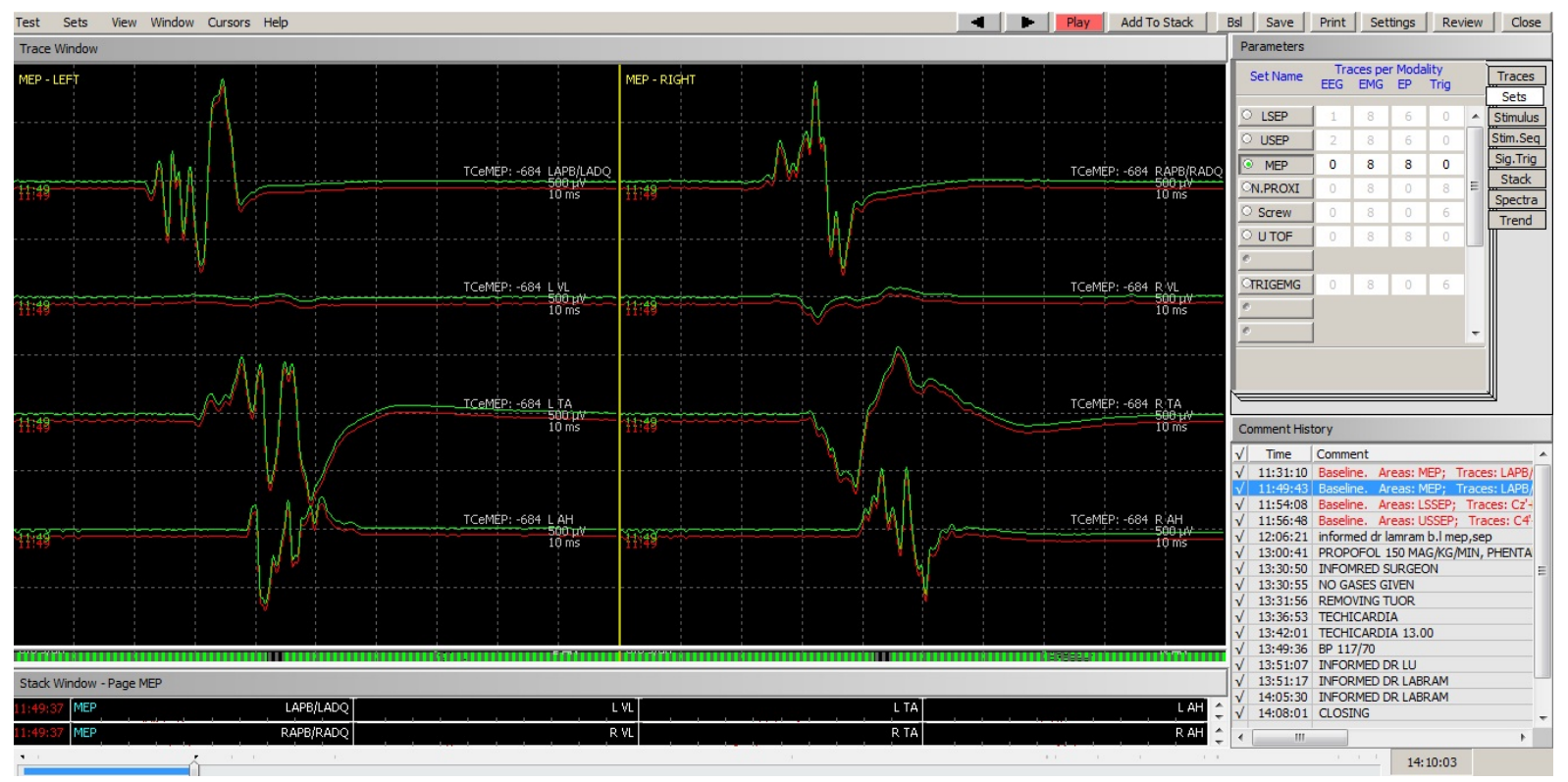

Figure 3. MEPs recordings prior to dissection of tumour. Baseline recordings in red and intraoperative recordings in green. 


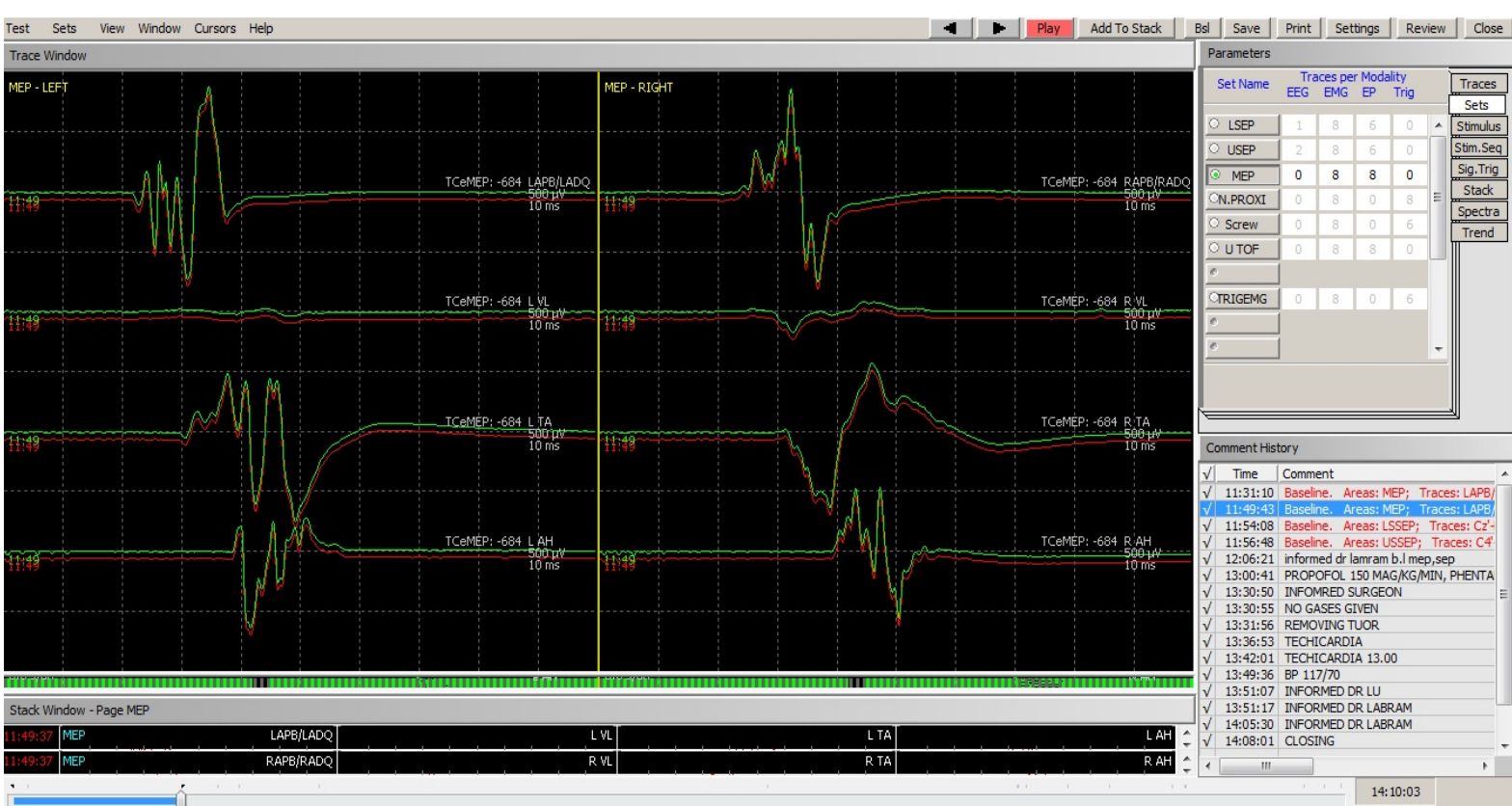

Figure 4. Changes in free-running EMG preceding changes in MEPs.

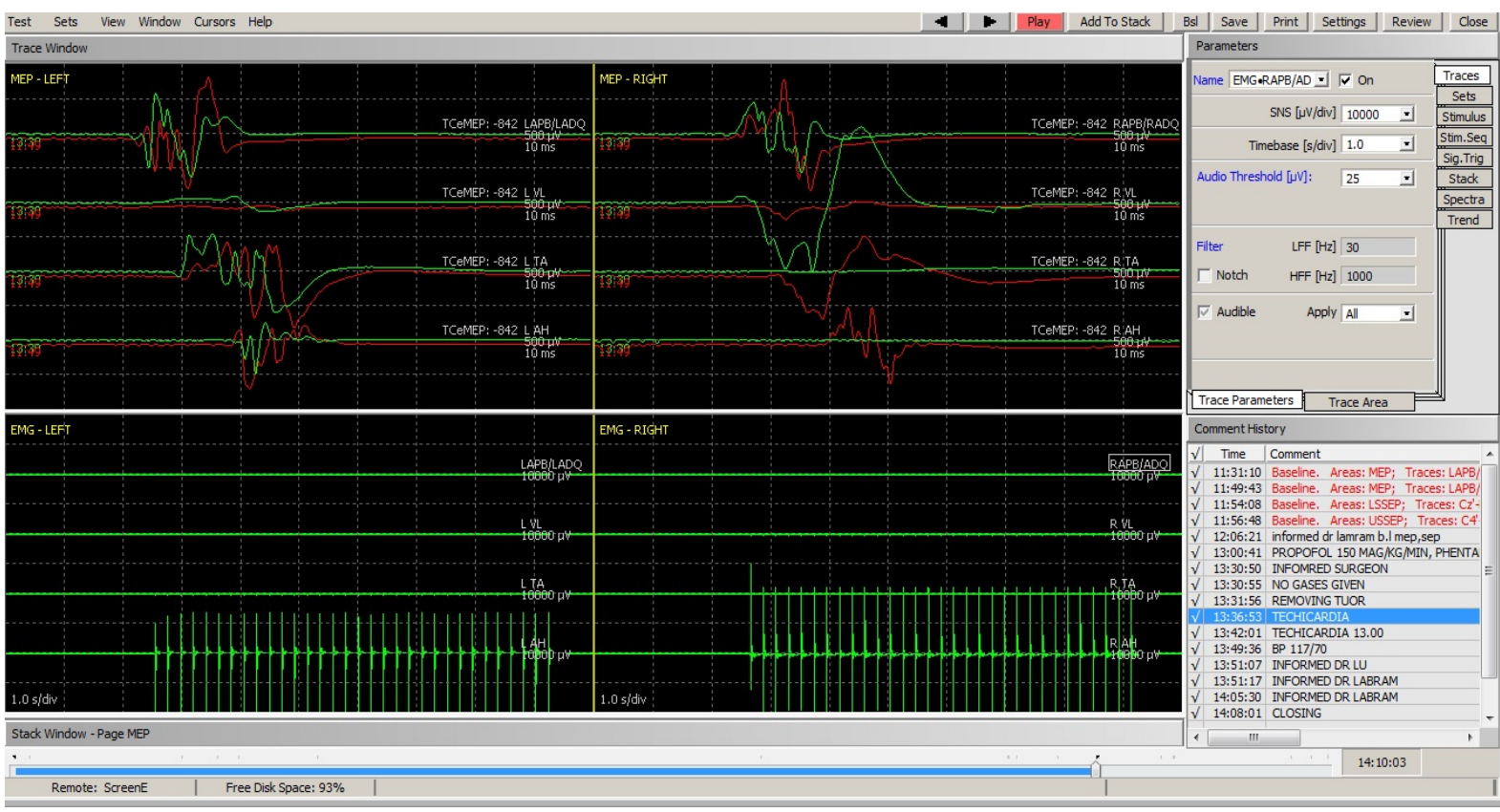

Figure 5. Stabilisation of EMG and MEPs recordings after 30 minutes.

\section{Conclusion}

There have been significant technological advances in IONM in the last three decades. This has enabled us to obtain more reliable intra-operative information about the sensory and motor pathways of the spinal cord during intramedullary spinal cord surgical procedures. The gold standard for intramedullary spinal cord tumour surgery will be to combine SSEPs, MEPs and D-wave monitoring. However, as illustrated by our small series, one can still achieve a good result even if D-wave monitoring is not available and free-running EMG and mMEPs monitoring are used. We also confirm that changes in the free-running EMG do precede any changes in the MEPs and should alert the surgical team to take appropriate actions to obviate and minimise injury to the spinal cord. 


\section{Acknowledgements}

We express our gratitude to the neurophysiology lab technicians (Zaitoon Shivji and Qurban Ali) for providing perioperative monitoring for our patients.

\section{References}

[1] Brotchi, J. (2002) Intrinsic Spinal Cord Tumour Resection. Neurosurgery, 50, 1059-1063.

[2] Jellinek, D., Jewkes, D. and Symon, L. (1991) Non-Invasive Intraoperative Monitoring of Motor Evoked Potentials under Propofol Anaesthesia: Effect of Spinal Surgery on the Amplitude and Latency of Motor Evoked Potentials. Neurosurgery, 29, 551-557. http://dx.doi.org/10.1227/00006123-199110000-00011

[3] Quinones-Hinojosa, A., Lyon, R., Gulati, M., Gupta, N. and Yingling, C. (2002) Spinal Cord Mapping as an Adjunct for Resection of Intramedullary Spinal Cord Tumors. Neurosurgery, 51, 1199-1206. http://dx.doi.org/10.1097/00006123-200211000-00015

[4] Kothbauer, K.F., Deletis, V. and Epstein, F.J. (1997) Intraoperative Spinal Cord Monitoring for Intramedullary Surgery: An Essential Adjunct. Pediatric Neurosurgery, 26, 247-254.

[5] Elsberg, C.A. and Beer, E. (1911) The Operability of Intramedullary Tumors of the Spinal Cord: A Report of Two Operations with Remarks upon the Extrusion of Inraspinal Tumours. The American Journal of the Medical Sciences, 142, 636-647. http://dx.doi.org/10.1097/00000441-191111000-00002

[6] Constantini, S., Miller, D.C., Allen, J.C., Rorke, L.B., Freed, D. and Epstein, F.J. (2000) Radical Excision of Intramedullary Spinal Cord Tumors: Surgical Morbidity and Long-Term Follow-Up Evaluation in 164 Children and Young Adults. Journal of Neurosurgery, 93, 183-193. http://dx.doi.org/10.3171/spi.2000.93.2.0183

[7] Epstein, F.J., Farmer, J.-P. and Freed, D. (1993) Adult Intramedullary Spinal Cord Ependymoma: The Results of Surgery in 38 Patients. Journal of Neurosurgery, 79, 204-209. http://dx.doi.org/10.3171/jns.1993.79.2.0204

[8] Raco, A., Esposito, V., Lenzi, J., Piccirilli, M., Delfini, R. and Cantore, G. (2005) Long-Term Follow-Up of Intramedullary Spinal Cord Tumors: A Series of 202 Cases. Neurosurgery, 56, 972-981.

[9] Deletis, V. and Sala, F. (2008) Intraoperative Neurophysiological Monitoring of the Spinal Cord during Spinal Cord and Spine Surgery: A Review Focus on the Corticospinal Tracts. Clinical Neurophysiology, 119, 248-264. http://dx.doi.org/10.1016/j.clinph.2007.09.135

[10] Pearce, J.M. (2001) Emil Heinrich Du Bois-Reymond (1818-1896). Journal of Neurology, Neurosurgery Psychiatry, 71, 620. http://dx.doi.org/10.1136/jnnp.71.5.620

[11] Dawson, G.D. (1950) Cerebral Responses to Nerve Stimulation in Man. British Medical Bulletin, 6, 326-329.

[12] Tamaki, T. and Kubota, S. (2007) History of the Development of Intraoperative Spinal Cord Monitoring. European Spine Journal, 16, 140-146. http://dx.doi.org/10.1007/s00586-007-0416-9

[13] Burke, D., Hicks, R., Stephen, J., Woodforth, I. and Crawford, M. (1992) Assessment of Corticospinal and Somatosensory Conduction Simultaneously during Scoliosis Surgery. Electroencephalography and Clinical Neurophysiology, 85, 388-396. http://dx.doi.org/10.1016/0168-5597(92)90052-D

[14] Morota, N., Deletis, V., Constantini, S., Kofler, M., Cohen, H. and Epstein, F.J. (1997) The Role of Motor Evoked Potentials during Surgery for Intramedullary Spinal Cord Tumors. Neurosurgery, 41, 1327-1336. http://dx.doi.org/10.1097/00006123-199712000-00017

[15] Owen, J.H. (1999) The Application of Intraoperative Monitoring during Surgery for Spinal Deformity. Spine, 24, 2649-2662. http://dx.doi.org/10.1097/00007632-199912150-00012

[16] Pelosi, L., Lamb, J., Grevitt, M., Mehdian, S., Webb, J. and Blumhardt, L. (2002) Combined Monitoring of Motor and Somatosensory Evoked Potentials in Orthopaedic Spinal Surgery. Clinical Neurophysiology, 113, 1082-1091. http://dx.doi.org/10.1016/S1388-2457(02)00027-5

[17] Merton, P.A. and Morton, H.B. (1980) Stimulation of the Cerebral Cortex in the Intact Human Subject. Nature, 285, 227. http://dx.doi.org/10.1038/285227a0

[18] Skinner, S., Nagib, M., Bergman, T., Maxwell, R. and Msangi, G. (2005) The Initial Use of Free-Running Electromyography to Detect Early Motor Tract Injury during Resection of Intramedullary Spinal Cord Lesions. Neurosurgery, 56, 299-314. http://dx.doi.org/10.1227/01.NEU.0000156545.33814.8D

[19] Wiedemayer, H., Fauser, B., Sandalcioglu, I.E., Schafer, H. and Stolke, D. (2002) The Impact of Neurophysiological Intraoperative Monitoring on Surgical Decisions: A Critical Analysis of 423 Cases. Journal of Neurosurgery, 96, 255-262. http://dx.doi.org/10.3171/jns.2002.96.2.0255

[20] Lesser, R.P., Raudzens, P., Luders, H., Nuwer, M.R., Goldie, W.D., Morris, H.H., Dinner, D.S., Klem, G., Hahn, J.F., Shetter, A.G., Ginsburg, H.H. and Gurd, A.R. (1986) Postoperative Neurological Deficits May Occur Despite Un- 
changed Intraoperative Somatosensory Evoked Potentials. Annals of Neurology, 19, 22-25. http://dx.doi.org/10.1002/ana.410190105

[21] Kearse Jr., L.A., Lopez-Bresnahan, M., McPeck, K. and Tambe, V. (1993) Loss of Somatosensory Evoked Potentials during Intramedullary Spinal Cord Surgery Predicts Postoperative Neurologic Deficits in Motor Function. Journal of Clinical Anesthesia, 5, 392-398. http://dx.doi.org/10.1016/0952-8180(93)90103-L

[22] Deletis, V. (2002) Intraoperative Neurophysiology and Methodologies Used to Monitor the Functional Integrity of the Motor System: Neurophysiology in Neurosurgery: A Modern Intraoperative Approach. Academic, San Diego, 25-51.

[23] Taniguchi, M., Nadstawek, J., Langenbach, U., Bremer, F. and Schramm, J. (1993) Effects of Four Intravenous Anesthetic Agents on Motor Evoked Potentials Elicited by Magnetic Transcranial Stimulation. Neurosurgery, 33, 407-415. http://dx.doi.org/10.1227/00006123-199309000-00009

[24] Calancie, B., Harris, W., Brindle, G.F., Green, B.A. and Landy, H.J. (2001) Threshold-Level Repetitive Transcranial Electrical Stimulation for Intraoperative Monitoring of Central Motor Conduction. Journal of Neurosurgery, 95, 161-168. http://dx.doi.org/10.3171/spi.2001.95.2.0161

[25] Macdonald, D.B. (2006) Intraoperative Motor Evoked Potential Monitoring: Overview and Update. Journal of Clinical Monitoring and Computing, 20, 347-377. http://dx.doi.org/10.1007/s10877-006-9033-0

[26] Sala, F., Bricolo, A., Faccioli, F., Lanteri, P. and Gerosa, M. (2007) Surgery for Intramedullary Spinal Cord Tumors: the Role of Intraoperative (Neurophysiological) Monitoring. European Spine Journal, 16, S130-S139. http://dx.doi.org/10.1007/s00586-007-0423-X

[27] Kothbauer, K.F., Deletis, V. and Epstein, F.J. (1998) Motor-Evoked Potential Monitoring for Intramedullary Spinal Cord Tumor Surgery: Correlation of Clinical and Neurophysiological Data in a Series of 100 Consecutive Procedures. Neurosurgical Focus, 4, e1.

[28] Quinones-Hinojosa, A., Lyon, R., Zada, G., Lamborn, K.R., Gupta, N., Parsa, A.T., McDermott, M.W. and Weinstein, P.R. (2005) Changes in Transcranial Motor Evoked Potentials during Intramedullary Spinal Cord Tumor Resection Correlate with Postoperative Motor Function. Neurosurgery, 56, 982-993.

[29] Sala, F., Palandri, G., Basso, E., Lanteri, P., Deletis, V., Faccioli, F. and Bricolo, A. (2006) Motor Evoked Potential Monitoring Improves Outcome after Surgery for Intramedullary Spinal Cord Tumors: A Historical Control Study. Neurosurgery, 58, 1129-1143. http://dx.doi.org/10.1227/01.NEU.0000215948.97195.58

[30] Calancie, B. and Molano, M.R. (2008) Alarm Criteria for Motor-Evoked Potentials: What's Wrong with the "Presence-or-Absence” Approach? Spine, 33, 406-414. http://dx.doi.org/10.1097/BRS.0b013e3181642a2f

[31] Pajewski, T.N., Arlet, V. and Phillips, L.H. (2007) Current Approach on Spinal Cord Monitoring: The Point of View of the Neurologist, the Anesthesiologist and the Spine Surgeon. European Spine Journal, 16, 115-129.

http://dx.doi.org/10.1007/s00586-007-0419-6 
Scientific Research Publishing (SCIRP) is one of the largest Open Access journal publishers. It is currently publishing more than 200 open access, online, peer-reviewed journals covering a wide range of academic disciplines. SCIRP serves the worldwide academic communities and contributes to the progress and application of science with its publication.

Other selected journals from SCIRP are listed as below. Submit your manuscript to us via either submit@scirp.org or Online Submission Portal.
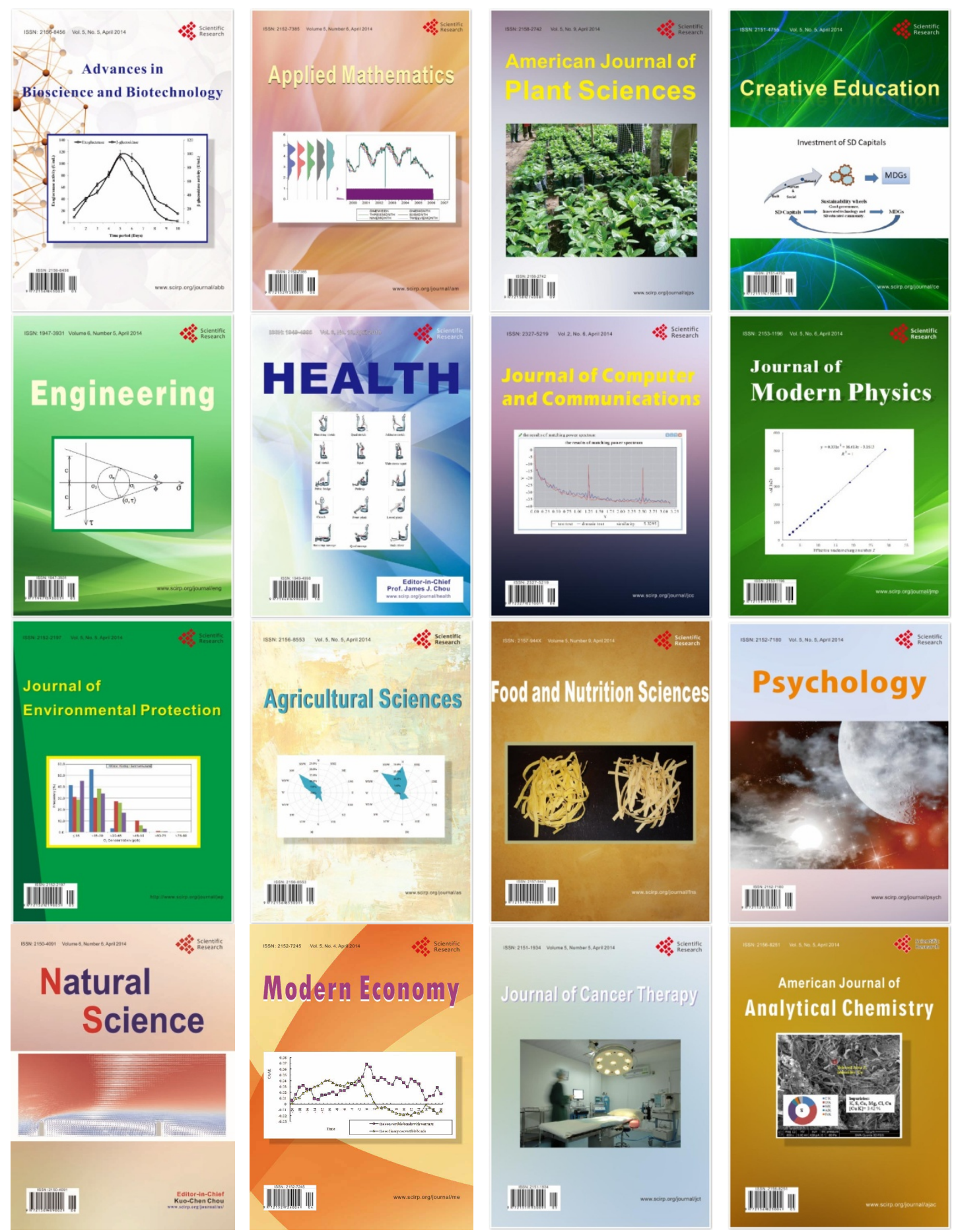